\title{
Inter-device reproducibility of retrobulbar blood flow velocity measurements in healthy subjects using color Doppler imaging
}

\author{
Verticchio Vercellin Alice C. ${ }^{1}$ Carlo A. Cutolo ${ }^{2} \cdot$ Carolina Dellafiore $^{3}$. \\ Massimiliano Lava ${ }^{3}$ Carmine Tinelli ${ }^{4}$ - Annalisa De Silvestri ${ }^{4} \cdot$ Fabrizio Calliada $^{3}$. \\ Giovanni Milano ${ }^{1}$
}

Received: 17 August 2015/ Accepted: 11 January 2016/Published online: 1 February 2016

(C) Società Italiana di Ultrasonologia in Medicina e Biologia (SIUMB) 2016

\begin{abstract}
Purpose To evaluate the inter-device reproducibility of retrobulbar blood flow measurements obtained by two commercially available CDI (color Doppler imaging) devices.

Methods The right eyes of 10 healthy volunteers were investigated. Four examiners, namely two ophthalmologists and two radiologists, performed CDI examination of the ophthalmic artery, central retinal artery and temporal short posterior ciliary arteries using both CDI devices: ESAOTE MYLAB ${ }^{\mathrm{TM}}$ and SIEMENS ANTARES STELLAR PLUS $^{\mathrm{TM}}$. The peak systolic velocity (PSV), the enddiastolic velocity (EDV) and the resulting resistivity index (RI) were averaged for 3 cardiac cycles. To evaluate the reproducibility between both device measurements, the Lin's concordance correlation coefficient (CCC) was used. CCC can be expressed as the product of Pearson's $r$ (the measure of precision) and C_b (the measure of accuracy). Results Results show that the inter-device reproducibility for CDI measurements is not acceptable since a poor degree of overall concordance $(0.15<\mathrm{CCC}<0.37)$ was obtained: accuracy was high $\left(\mathrm{C}_{-} \mathrm{b}>0.71\right)$ but overall
\end{abstract}

Verticchio Vercellin Alice C.

alice.verticchio@gmail.com;

alicechandra.verticchio01@ateneopv.it

1 University Eye Clinic, Foundation IRCCS Policlinico San Matteo, Piazzale Golgi 19, 27100 Pavia, Italy

2 University Eye Clinic, DiNOGMI, University of Genoa, Genoa, Italy

3 Institute of Radiology, Foundation IRCCS Policlinico San Matteo, Pavia, Italy

4 Clinical Epidemiology and Biometric Unit, Foundation IRCCS Policlinico San Matteo, Pavia, Italy precision low $(0.18<$ Pearson's $r<0.47)$. Ophthalmologists and radiologists obtained similar results.

Conclusions To evaluate the causal role of blood flow abnormalities in glaucoma, CDI analysis using different devices seems unreliable. CDI inter-device reproducibility seems unrelated to medical speciality of the examiners. However, to improve present results, the use of similar probes and standardized CDI instrument settings as well as a CDI images analysis by a single grader, might possibly improve the inter-device reproducibility when testing the retrobulbar blood flow velocity.

Keywords Blood flow velocity - Doppler ultrasound imaging · Glaucoma $\cdot$ Healthy volunteers $\cdot$ Reproducibility of results

\begin{abstract}
Scopo Valutare la riproducibilità delle misurazioni delle velocità di flusso ematico nei vasi retrobulbari di volontari sani: le misurazioni sono state ottenute con due diverse strumentazioni ecografiche commercialmente disponibili.

Materiali e Metodi Quattro operatori, due radiologi e due oculisti, hanno misurato le velocità di flusso nell'arteria oftalmica (AO), nell'arteria centrale della retina (ACR) e nelle arterie ciliari posteriori brevi (ACPB) in 10 occhi di volontari sani utilizzando due ecografi: ESAOTE MYLAB ${ }^{\mathrm{TM}}$ and SIEMENS ANTARES STELLAR PLUS ${ }^{\mathrm{TM}}$. Sono state calcolate le medie di 3 cicli cardiaci dei parametri di flusso PSV (velocità di picco sistolico), EDV (velocità di fine diastole) e IR (indice di resistività). Per valutare la riproducibilità delle misure effettuate con le due strumentazioni è stato calcolato il coefficiente di correlazione di Lin (CCC). Il CCC può essere espresso come
\end{abstract}


il prodotto del coefficiente di Pearson's r (misura della precisione) e C_b (misura dell'accuratezza).

Risultati I risultati mostrano che la riproducibilità delle misurazioni tra due ecografi non è accettabile dal momento che è stato ottenuto uno scarso grado di concordanza $(0.15<\mathrm{CCC}<0.37)$ : il grado di accuratezza è alto (C_b $>0.71)$ mentre il grado di precisione basso $(0.18<$ Pearson's $r<0.47$ ). Oculisti e radiologi hanno ottenuto risultati simili.

Conclusioni Per valutare il ruolo causale delle anomalie di flusso ematico nella patogenesi della neuropatia ottica glaucomatosa l'utilizzo di diverse strumentazioni ecografiche appare inaffidabile. La riproducibilità delle misurazioni ottenute con diversi macchinari non sembra correlata con la specialità medica dell'esaminatore. L'uso di sonde simili, di settings CDI standardizzati e l'analisi delle immagini da parte di un singolo operatore potrebbero essere accorgimenti adeguati per migliorare i risultati attuali e quindi per migliorare la riproducibilità inter-device delle velocità di flusso nei vasi retrobulbari.

\section{Introduction}

Primary open-angle glaucoma (POAG) is a chronic, progressive optic neuropathy with a characteristic acquired loss of optic nerve fibres that may lead to severe visual impairment or blindness [1]. Intra-ocular pressure (IOP) has been consistently demonstrated to be associated with incidence, prevalence, and progression of POAG [2] and IOP reduction is the cornerstone for glaucoma therapy [3]. However, POAG patients can continue to experience optic nerve damage in spite of successful IOP lowering [4]. Conversely, up to $95 \%$ of individuals with statistically elevated IOP do not suffer from open-angle glaucoma and the large majority of them will not develop the disease [5]. Moreover, up to $15-25 \%$ of patients affected by POAG, experience consistently normal IOP [6].

All these evidences together resulted in the view that other factors, such as ischemia, play an important role in the pathogenesis of POAG [5].

Color Doppler imaging (CDI) is a non-invasive technique used to evaluate blood flow of the eye, not affected by poor ocular media, with acceptable intra-observer reproducibility [7] which shows perfusion abnormalities in POAG patients [8, 9]. Despite this, it is difficult to establish the causal role of ischemia in glaucoma.

To the best of our knowledge, no previous studies have been carried out to test reproducibility of retrobulbar blood flow measurements obtained by operators with a different medical speciality (radiologists and ophthalmologists) using two different available CDI devices (ESAOTE
MYLAB $^{\text {TM }}$, probe LA533 13-6 MHz small parts-vascular linear array and SIEMENS ANTARES STELLAR PLUS $^{\mathrm{TM}}$, probe VFX 9-4 MHz vascular linear array) and assessing the ophthalmic artery (OA), central retinal artery (CRA) and temporal short posterior ciliary arteries (TSPCA). we verified the inter-device reproducibility using the devices that we could use in our clinic in healthy subjects because we wanted to evaluate physiological retrobulbar flow parameters which we wanted to be not (or the least possible) influenced by pathological conditions (for example, atherosclerosis).

The aim of our study was to evaluate the inter-device reproducibility of CDI in assessing blood flow velocity in the OA, the CRA, and the TSPCA in healthy volunteers. The study was carried out using two different CDI devices and four masked operators with two different medical specialities.

\section{Materials and methods}

\section{Participants}

The right eyes (RE) of 10 healthy volunteers of both sexes aged over 18 years and without systemic or ocular diseases were investigated. The research followed the tenets of Declaration of Helsinki and informed consent was obtained from all the subjects after explanation of the nature and possible consequences of the study. The study was carried out at the Department of Ophthalmology and Institute of Radiology of the IRCCS Policlinico San Matteo Foundation in Pavia in 2013. Subjects were interviewed for demographics, ophthalmic history, systemic diseases and systemic medications. Ocular measurements included best-corrected visual acuity (BCVA) with Early Treatment Diabetic Retinopathy Study (ETDRS) charts, slit-lamp examination, Goldmann applanation tonometry, gonioscopy and non-dilated fundus examination. All subjects were classified as healthy based on: free of ocular pathology in either eye, no family history for glaucoma, BCVA $>85$ letters (ETDRS) in both eyes, IOP $<21 \mathrm{mmHg}$ in either eye, no systemic pathologies or use of any topical or systemic medications. Each subject was asked to refrain from smoking and caffeine intake for at least $1 \mathrm{~h}$ prior to CDI examination to minimize the influence of these factors on the blood flow $[10,11]$.

\section{Data collection}

Four examiners, namely two ophthalmologists and two radiologists, performed CDI measurements assessing the OA, CRA and TSPCA of 10 eyes using both CDI devices: ESAOTE MYLAB ${ }^{\mathrm{TM}}$ (probe LA533 13-6 MHz small parts-vascular linear array) and SIEMENS ANTARES STELLAR PLUS ${ }^{\mathrm{TM}}$ (probe VFX 9-4 MHz vascular linear 
array). Examiners, blinded to each other's findings, performed CDI measurements of peak systolic velocity (PSV), end-diastolic velocity (EDV) and resistivity index (RI) of OA, CRA and TSPCA.

The measurements were performed with standard Doppler technique, with inclination of the colour box in the flow direction and an angle comprised between 30 and $60^{\circ}$.

The order in which the exams were performed was randomized. Subject's CDI measurements were obtained within $90 \mathrm{~min}$. Before the study the intra-observer concordance was tested and all the examiners showed an acceptable degree of reproducibility with both devices [12]. Examiners conducted the examination in accordance with the methods reported by previous investigations [7].

\section{Statistical analysis}

Power consideration: a sample size of 10 subjects with 8 observations per subject achieves more than $90 \%$ power to detect a difference of concordance correlation coefficient of 0.15 (null hypothesis 0.80 versus alternative hypothesis 0.95 ) using an $F$ test with a significance level of 0.05 .

All measurements were averaged for 3 cardiac cycles. The Shapiro-Wilk test was used to test the normal distribution of quantitative variables; since they were normally distributed, the results were expressed as mean values and $\mathrm{SD}$, also the \% coefficient of variation (CV) was calculated; qualitative variables were summarized as counts and percentages.

Inter-device reproducibility was assessed through the calculation of the concordance correlation coefficient
(Lin's coefficient, CCC, rho_c) [13]. The CCC combines measures of both precision and accuracy to determine how far the observed data deviate from the line of perfect concordance (i.e. the line at 45 degrees on a square scatterplot). Lin's coefficient increases in value as a function of the nearness of the best-fit line to the line of perfect concordance (the accuracy of the data) and of the tightness of the data about its reduced major axis (the precision of the data). The Pearson correlation coefficient, $r$; the bias-correction factor, $\mathrm{C}_{-} \mathrm{b}$; and the equation of the reduced major axis are reported to show these components. The CCC can be expressed as the product of Pearson's $r$ (the measure of precision) and $\mathrm{C}_{-} \mathrm{b}$ (the measure of accuracy). $\mathrm{CCC}$ ranges in values from 0 to +1 . A CCC value of 0 indicates that most of the error originates from differences in measurements between operators. As CCC values approach 1, the measurement differences between the different operators are becoming negligible and more consistent. Inter-device reproducibility agreement was classified as poor $(\mathrm{CCC}<0.40)$, fair to good $(0.40<\mathrm{CCC}<0.75)$ or excellent $(\mathrm{CCC}>0.75)$ [14]. The CCCs were reported with a $95 \%$ confidence interval (CI).

\section{Results}

The enrolled subjects were five males and five females (mean age 24 years, SD 2.62; mean IOP $15.9 \mathrm{mmHg}$, SD 1.85).

The mean intrasubject $\mathrm{CV}$ of measurements relative to the three consecutive cardiac cycles for each parameter

Table 1 Summary of measurements; overall inter-device intra-observer concordance

\begin{tabular}{|c|c|c|c|c|c|c|c|c|c|c|}
\hline $\begin{array}{l}\text { Vessel, } \\
\text { parameter }\end{array}$ & $\begin{array}{l}\text { Esaote (mean, sd) } \\
{[\mathrm{cm} / \mathrm{s}]}\end{array}$ & $\begin{array}{l}\text { Siemens (mean, sd) } \\
{[\mathrm{cm} / \mathrm{s}]}\end{array}$ & $\mathrm{CCC}$ & $\begin{array}{l}\text { CCC } 95 \% \\
\text { CI }\end{array}$ & $\begin{array}{l}\text { Pearson's } r \\
\text { (precision) }\end{array}$ & $\begin{array}{l}\text { C_b } \\
\text { (accuracy) }\end{array}$ & LOA & \multicolumn{3}{|c|}{ LOA CCC $95 \%$ CI } \\
\hline OA PSV & 35.76 (SD 7.48) & $35.42(\mathrm{SD} 8.01)$ & 0.237 & $\begin{array}{l}-0.062 \text { to } \\
0.536\end{array}$ & 0.238 & 0.996 & 0.340 & -18.43 & - & 19.11 \\
\hline OA EDV & 9.29 (SD 3.27) & 8.34 (SD 2.57) & 0.208 & $\begin{array}{c}-0.072 \text { to } \\
0.488\end{array}$ & 0.226 & 0.920 & 0.954 & -6.17 & - & 8.08 \\
\hline OA RI & 0.74 (SD 0.07) & 0.76 (SD 0.05) & 0.312 & $0.051-0.573$ & 0.344 & 0.908 & -0.022 & -0.15 & - & 0.11 \\
\hline CRA PSV & $10.81(\mathrm{SD} 2.38)$ & 9.33 (SD 2.28) & 0.15 & $\begin{array}{l}-0.107 \text { to } \\
0.406\end{array}$ & 0.182 & 0.822 & 1.489 & -4.27 & - & 7.25 \\
\hline CRA EDV & 4.15 (SD 1.43) & 3.16 (SD 1.03) & 0.339 & $\begin{array}{c}0.135 \text { to } \\
0.542\end{array}$ & 0.474 & 0.714 & 0.983 & -1.54 & - & 3.50 \\
\hline CRA RI & 0.62 (SD 0.08) & 0.66 (SD 0.09) & 0.268 & $\begin{array}{l}-0.001 \text { to } \\
0.537\end{array}$ & 0.295 & 0.908 & -0.035 & -0.23 & - & 0.16 \\
\hline TSPCA PSV & 14.29 (SD 2.93) & 14.19 (SD 3.18) & 0.277 & $\begin{array}{l}-0.015 \text { to } \\
0.569\end{array}$ & 0.278 & 0.995 & 0.098 & -7.08 & - & 7.28 \\
\hline $\begin{array}{l}\text { TSPCA } \\
\text { EDV }\end{array}$ & $5.52(\mathrm{SD} 1.81)$ & 5.35 (SD 2.15) & 0.319 & $0.04-0.599$ & 0.326 & 0.979 & 0.174 & -4.31 & - & 4.66 \\
\hline TSPCA RI & $0.62(\mathrm{SD} 0.08)$ & 0.63 (SD 0.10) & 0.367 & $0.102-0.631$ & 0.380 & 0.963 & -0.013 & -0.20 & - & 0.17 \\
\hline
\end{tabular}

$C C C$ concordance correlation coefficient, $C I$ confidence interval, $C R A$ central retinal artery, $E D V$ end-diastolic velocity, $L O A$ limits of agreement, $O A$ ophthalmic artery, $P S V$ peak systolic velocity, TPCA temporal short posterior ciliary arteries, $R I$ resistivity index, $S D$ standard deviation 

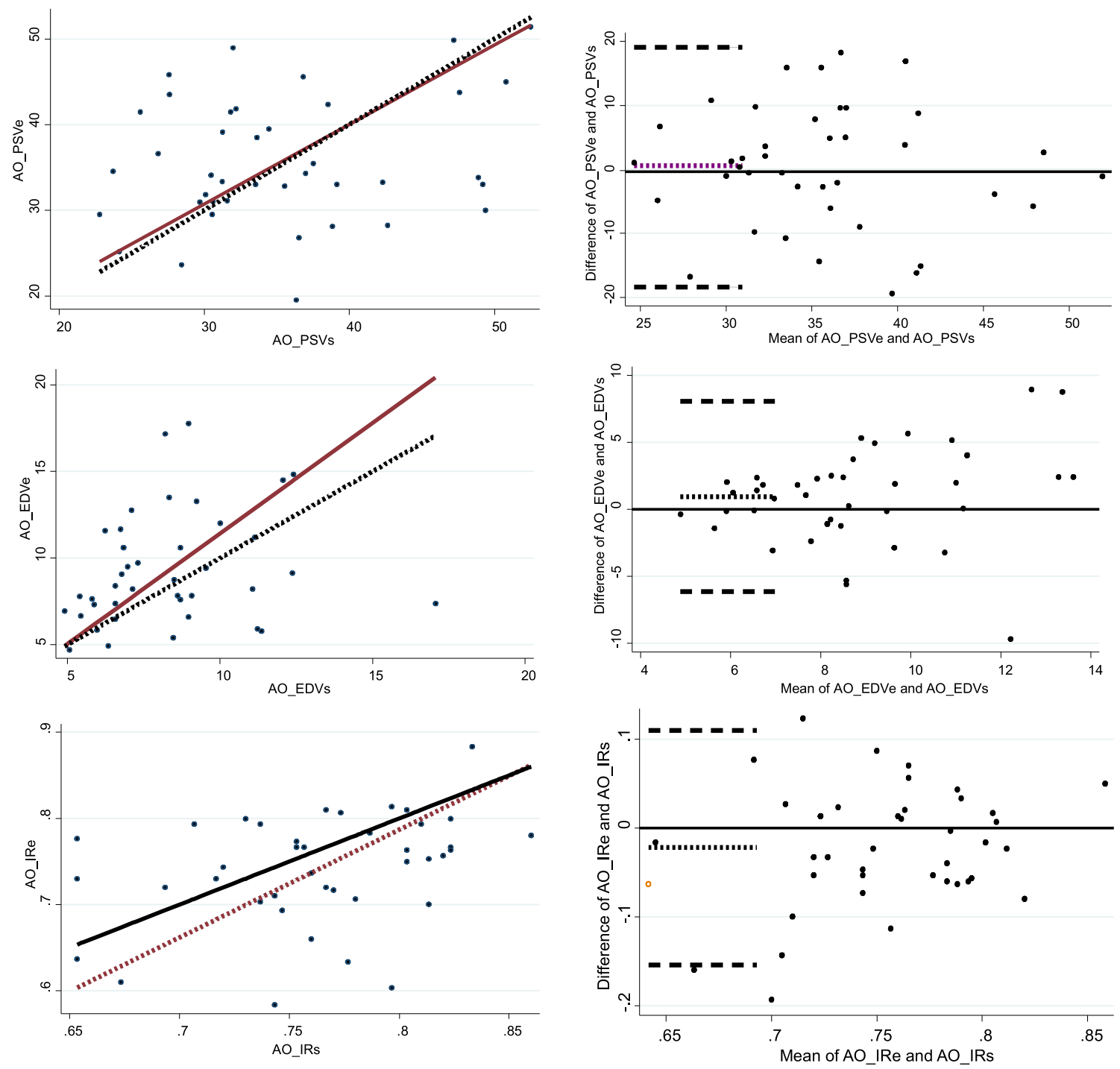

Fig. 1 Right Overall inter-device reproducibility between Esaote and Siemens devices. The solid line is the best-fit line and the dotted line is the line of perfect agreement. Left Bland-Altman plot of differences in ratings between devices. The solid line $(y=0)$ is a

in each vessel ranged from 3 to $7 \%$, while the intrasubject $\mathrm{CV}$ relative to the measure taken by different operators and device at different times ranged from 11 to $31 \%$.

To test if two different devices provide comparable data, the overall inter-device CCC obtained by the examiners for each parameter in each vessel was calculated. The mean of velocities and RIs measured by the two devices are presented in Table 1 along with the overall inter-device CCC, Pearson's r, C_b and Limits of Agreement (LOA). Results show that the inter-device reproducibility for CDI measurements is not acceptable since a poor degree of overall concordance $(0.15<\mathrm{CCC}<0.37)$ was obtained: accuracy was high $\left(\mathrm{C}_{-} \mathrm{b}>0.71\right)$ but overall precision low $(0.18<$ Pearson's $\mathrm{r}<0.47)$. Ophthalmologists and radiologists

line of perfect average agreement. The dotted line represents the mean of difference of ratings. The dashed lines define the limits of agreement [mean of the differences (2 SD)]

obtained similar results when evaluating inter-device reproducibility.

Figure 1 shows overall inter-device reproducibility between Esaote and Siemens devices (on the right) and the Bland-Altman plot of differences in ratings between devices (on the left).

\section{Discussion}

Present results suggest that CDI analysis reproducibility using different devices seems poorly acceptable. Mainly, inter-device concordance is adversely affected by low precision of measurements and this fact could be explained 
by technical differences between devices or operator-dependent variables. Since the intrasubject $\mathrm{CV}$ of measurements relative to the three consecutive cardiac cycles taken by the same operator on the same device is about ten times lower than the intrasubject $\mathrm{CV}$ relative to the measure taken by different operators and device at different times we can speculate that the low precision observed in this study could be partially due to the high intrasubject variability.

As a consequence, data obtained by different centers using different CDI devices could not be comparable.

The RI is a dimensionless measure calculated from the velocity measurements (PSV, and EDV) with the following formula: $\mathrm{RI}=(\mathrm{PSV}-\mathrm{EDV}) / \mathrm{PSV}$. Our results show that there is a difference in velocity measurements between the two instruments and, as a consequence, even the RIs have been affected by the error because they are derived from velocity measurements.

On the other hand, a local normative database developed by a single laboratory could become unusable when a new CDI device replaces the old one.

The causal role of ischemia in glaucoma may be confirmed performing long-term prospective studies that could help to clarify whether POAG or vasculature perfusion alterations came first as well as large multicentre studies designed to ameliorate blood flow that could prove a beneficial clinical outcome [5].

These types of studies require data collection of numerous exams performed by different examiners likely using various devices.

As a matter of fact, CDI devices are widely used in medicine and the technique has shown good reproducibility, after adequate training, even for measurements of retrobulbar blood flow velocity obtained by the same observer in the same patient $[15,16]$.

Inter-observer reproducibility is generally less satisfactory. However, highly reproducible results for PSV and EDV in OA and CRA have been reported in a recent study where a rigorous protocol was established, an intensive training was performed by an expert and CDI images were analysed by a single masked grader [17].

\section{Conclusion}

In conclusion, CDI measurements using different device to evaluate the causal role of blood flow abnormalities in glaucoma, seems unreliable. However, to improve present results during multicentre or long-term studies, the use of similar probes and standardized CDI instrument settings, as well as a CDI images analysis by a single grader, might possibly improve the inter-device reproducibility when testing the retrobulbar blood flow velocity.
Acknowledgments We thank the Centro per la Comunicazione e la Ricerca of the Ghislieri College of Pavia for supporting the project "Investigation of hemodynamics of the optic nerve with color Doppler imaging in normal tension glaucoma".

Conflict of interest The authors have no conflict of interest.

Informed consent All procedures followed were in accordance with the ethical standards of the responsible committee on human experimentation (institutional and national) and with the Helsinki Declaration of 1975 , as revised in 2000. Written informed consent was obtained from the patient for the publication of this case report and accompanying images.

Human and animal studies The study was conducted in accordance with all institutional and national guidelines for the care and use of laboratory animals.

\section{References}

1. European Glaucoma Society (2008) Terminology and guidelines for glaucoma, 3rd edn. Editrice Dogma, Savona

2. Medeiros FA. Glaucoma Risk Factors: Fluctuation in Intraocular Pressure. In: Schacknow PN, Samples JR. The Glaucoma Book: A Practical, Evidence-based Approach to Patient Care. New York Dordrecht Heidelberg London: Springer; 2010: 51-54

3. Beidoe G, Mousa SA (2012) Current primary open-angle glaucoma treatments and future directions. Clin Ophthalmol 6:1699-1707

4. Heijl A, Leske C, Bengtsson B, Hyman L, Bengtsson B, Hussein M (2002) Reduction of intraocular pressure and glaucoma progression: results from the Early Manifest Glaucoma Trial. Arch Ophthalmol 120:1268-1279

5. Chauhan BC. The Role of Ocular Blood Flow Abnormalities in the Pathogenesis of Glaucoma. In: Schmetterer L, Kiel JW. Ocular Blood Flow. New York Dordrecht Heidelberg London: Springer; 2012: 411-428

6. Hitchings RA. Normal Tension Glaucoma. In: Yanoff M, Duker JS. Ophthalmology. 3rd ed. London: Mosby Elsevier; 2008: 1159-1161

7. Stalmans I, Vandewalle E, Anderson DR et al (2011) Use of colour Doppler imaging in ocular blood flow research. Acta Ophthalmol 89:e609-e630

8. Galassi F, Nuzzaci G, Sodi A, Casi P, Vielmo A (1992) Color Doppler imaging in evaluation of optic nerve blood supply in normal and glaucomatous subjects. Int Ophthalmol 16:273-276

9. Garhöfer G, Fuchsjäger-Mayrl G, Vass C, Pemp B, Hommer A, Schmetterer L (2010) Retrobulbar blood flow velocities in open angle glaucoma and their association with mean arterial blood pressure. IOVS 51:6652-6657

10. Cryer PE, Haymond MW, Santiago JV, Shah SD (1976) Norepinephrine and epinephrine release and adrenergic mediation of smoking-associated hemodynamic and metabolic events. N Engl J Med 295:573-577

11. Terai N, Spoerl E, Pillunat LE, Stodtmeister R (2012) The effect of caffeine on retinal vessel diameter in young healthy subjects. Acta Ophthalmol 90:e524-e528

12. Dellafiore C, Lava M, Verticchio Vercellin AC, et al. Reproducibility of retrobulbar blood flow velocity measurements in normal subjects using two different CDI devices. Radiol Med. 2015 Feb 19. [epub ahead of print]

13. Li Lin (1989) A concordance correlation coefficient to evaluate reproducibility. Biometrics 45:255-268 
14. Fleiss JL. The Measurement of interrater Agreement. In: Fleiss JL. Statistical method for rates and proportions. New York: John Wiley and Sons; 1981: 211-236

15. Harris A, Williamson TH, Martin B et al (1995) Test/retest reproducibility of color Doppler imaging assessment of blood flow velocity in orbital vessels. J Glaucoma 4:281-286
16. Matthiessen ET, Zeitz O, Richard G, Klemm M (2004) Reproducibility of blood flow velocity measurements using colour decoded Doppler imaging. Eye. 18:400-405

17. Founti P, Harris A, Papadopoulou D et al (2011) Agreement among three examiners of colour Doppler imaging retrobulbar blood flow velocity measurements. Acta Ophthalmol 89:e631-e634 